\title{
Simultaneous minimization of arsenic mobilization and nitrous oxide emission under nitrogen fertilization in paddy soils
}

\author{
HANNA JOSS ${ }^{1}$, PRACHI JOSHI ${ }^{1}$, MARKUS MAISCH ${ }^{1}$, \\ YONG-GUAN ZHU 2,3 , E. MARIE MUEHE ${ }^{4}$, CHRISTIANE \\ ZARFL $^{1}$ AND ANDREAS KAPPLER $^{1}$ \\ ${ }^{1}$ University of Tuebingen \\ ${ }^{2}$ Research Center for Eco-environmental Sciences \\ ${ }^{3}$ Chinese Academy of Sciences \\ ${ }^{4}$ Helmholtz Centre for Environmental Research - UFZ \\ Presenting Author: hanna.joss@uni-tuebingen.de
}

The cultivation of rice as a staple food for millions of people will be intensified in the future to meet the global food demand arising from a growing population. Nitrogen fertilizers are commonly applied to paddy fields to increase rice yield, but also stimulate microbial (de-)nitrification, leading to intermediates such as nitrous oxide $\left(\mathrm{N}_{2} \mathrm{O}\right)$, that has over 300 times the climate effect of carbon dioxide on a per molecule basis over 100 years. Denitrification can also biotically and abiotically be coupled to the oxidation of iron(II), forming iron(III) minerals, which are strong adsorbents for (toxic) metals and metalloids, such as arsenic. As a consequence, arsenic, which is often naturally present in paddy soils, can be sequestered during the formation of iron(III) (oxyhydr)oxides by the addition of nitrogen fertilizer and by plant-induced oxidation of soil-borne iron(II) precipitating along rice roots by radial oxygen loss (ROL). When ROL ceases and nitrogen is depleted, arsenic is being remobilized during the microbial reduction of iron(III) minerals. Currently, it is still unknown how a balanced addition of nitrogen fertilizer can, at the same time, lower arsenic mobility while minimizing $\mathrm{N}_{2} \mathrm{O}$ release.

Thus, in this project we quantify and identify the iron(III) minerals formed during nitrogen fertilization, we determine the potential of these minerals to sequester arsenic in the rhizosphere and the bulk soil and evaluate the effects on $\mathrm{N}_{2} \mathrm{O}$ emissions over a plant growth period. Furthermore, we will elucidate the role of the native microbial community and determine the potential for and the competition between nitrate-reducing iron(II)-oxidizing and iron(III)-reducing microorganisms cultivated from native paddy soils. This will enable us to estimate the role of microorganisms on influencing arsenic mobility and $\mathrm{N}_{2} \mathrm{O}$ emissions.

By combining different approaches such as soil microcosms, (un-)planted rhizonboxes or rhizonboxes with artificial roots, different laboratory analyses on biogeochemical processes and mathematical modelling approaches, we will be able to identify the parameters crucial for arsenic mobilization and $\mathrm{N}_{2} \mathrm{O}$ emissions under nitrogen fertilization. This study will contribute to understanding the complex and dynamic redox processes present in paddy soils and to minimize health and environmental risks in rice paddy fields under nitrogen fertilization. 